\title{
Congenital Incomplete Sternal Cleft: About A Case Report and Review of the Literature
}

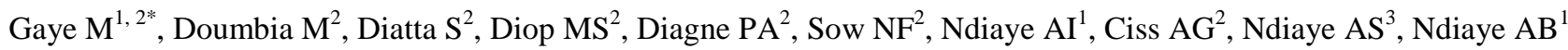

${ }^{1}$ Laboratory of Anatomy and Organogenesis of the Cheikh Anta Diop University of Dakar, Senegal

${ }^{2}$ Thoracic and Cardiovascular Surgery Department - Fann CHNU, Avenue Cheikh Anta Diop, Dakar, Senegal

${ }^{3}$ Laboratory of Anatomy and Organogenesis - UAS Ziguinchor, Ziguinchor, Senegal

DOI: $10.36347 /$ simcr.2020.v08i05.010

| Received: 08.05.2020 | Accepted: 15.05.2020 | Published: 17.05.2020

*Corresponding author: Magaye Gaye

Abstract

We report a case of incomplete sternal cleft with superior fissure of incidental discovery in a 3-year-old child. We study the pathophysiological, clinical and therapeutic aspects through a review of the literature.

Keywords: Sternal cleft, sternal fissure, Cantrell pentalogy.

Copyright @ 2020: This is an open-access article distributed under the terms of the Creative Commons Attribution license which permits unrestricted use, distribution, and reproduction in any medium for non-commercial use (NonCommercial, or CC-BY-NC) provided the original author and source are credited.

\section{INTRODUCTION}

The sternal clefts are rare malformations that result from a defect in the fusion of the sternal bars. This fusion normally takes place at the 9th week of intrauterine life in the cranio-caudal direction [1]. They can be diagnosed at birth or later. They occur in less than 1 in 50.000 children [2]. All parts of the sternum may be interested. They are most often isolated but can be associated with a facial hemangioma, webbed neck, malformations of the central nervous system or a coloboma of the eye. The sternal cleft can also be part of Cantrell's pentalogy [1]. The latter conditions the prognosis. There are rare family cases reported. The latter are associated with other malformations. The etiology is unknown. Surgical closure must be undertaken during the first weeks of life in order to protect the heart and the large vessels from any trauma, to improve respiratory dynamics but also for aesthetic reasons [2]. We report the case of an asymptomatic total congenital isolated sternal cleft and through this case, review the literature on the pathophysiological, clinical and therapeutic aspects.

\section{OBSERVATION}

$\mathrm{He}$ is a 3-year-old male patient, with no specific medical and surgical history, seen in consultation for a speech disorder. The physical examination found good psychomotor development and an absence of the sternal manubrium without muscular, costal and vertebral anomalies (Figure-1). The remainder of the physical examination was unremarkable and did not show any other abnormalities, including no supra-umbilical raphe, no facial hemangioma, no back static disorder. The chest scanner confirmed the diagnosis. The indication for a surgical closure was asked but due to a deficient technical platform, monitoring was recommended.

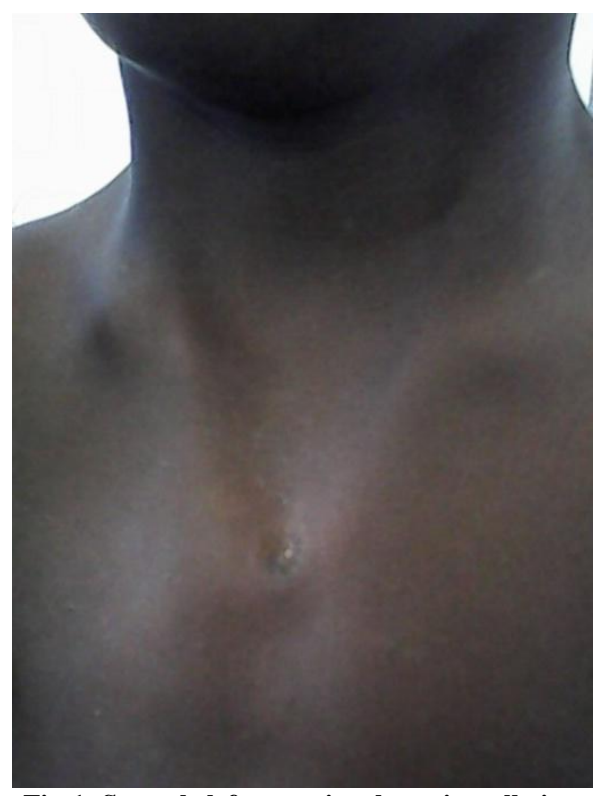

Fig-1: Sternal cleft: anterior thoracic wall view

\section{DiscuSSION}

The etiology of the sternal cleft is unknown Haque [3] suggested a multifactorial mechanism combining a riboflavin deficiency and an autosomal recessive inheritance with incomplete penetrance. 
Studies of the development of the chest wall have suggested the involvement of the Hoxb-4 gene. Alcohol absorption and methylcobalamin deficiency may also be involved $[4,5]$. The sternal cleft can be complete (the rarest form) or incomplete. The latter may be an upper fissure or bifid sternum ("V" or "U" shaped) or an isolated lower fissure or associated with other anomalies in the development of the anterior chest wall such as thoracic ectopia of the heart -abdominal. In our patient, there is an isolated upper slit [1]. The chest scanner made it possible to make the diagnosis. On the other hand, the contribution of medical imagery is decisive both for the diagnosis and for the preoperative morphological assessment [6]. The management of the sternal cleft is multidisciplinary, and associates anesthesiologists, physiotherapists, thoracic surgeons, plastic surgeons, even psychotherapists. In 1888, Lannelongue [7] made the first surgical repair of a complete sternal cleft. Two cases of surgical success by the installation of a cartilaginous graft, at the level of the osseous defect, were published by Burton [8] in 1947. In 1949, Maier and Bortone [9] had realized, in a child of 6 weeks, a direct approximation of the 2 hemisternums and this technique has become the reference.

The use of periosteal flaps has the advantage of slightly widening the thoracic perimeter, thus avoiding any compression [10]. Acastello [2] described a partial resection of the first 3 costal cartilages and a sterno-clavicular disarticulation in order to close the sternal cleft. Mathai [11] said that the integrity of the sternoclavicular joints prevents the hemi-sternums from coming together. He describes a lateral clavicular osteotomy at 6 weeks of life facilitating upper sternal closure without tension and avoiding a thoracic hernia without bringing together muscle flaps. The treatment of the sternal cleftt in the neonatal period is essential. During the first month of life, the chest wall is more compliant therefore the risk of compression of the intrathoracic organs is low. In view of these difficulties linked to surgery in the elderly, we favored medical surveillance in our patient, allowing growth to be complete.

\section{Conclusion}

The sternal cleft is a rare congenital malformation of the chest wall, the diagnosis of which is CT and its management must be early and rapid.
Conflicts of Interest: The authors of this article declare that there is no conflict of interests.

\section{Authorization of the ethics committee}

The Ethics Committee of our Faculty of Medicine gave us its agreement for the realization of this study.

The patient's parents on which were realized clinical examination gave their consent for the publication.

\section{REFERENCES}

1. Engum SA. Embryology, sternal clefts, ectopia cordis, and Cantrell's pentalogy. Semin Pediatr Surg, 2008; 17:154-60.

2. Acastello E, Majluf R, Garrido P, Barbosa LM, Peredo A. Sternal cleft: a surgical opportunity. Journal of pediatric surgery. 2003 Feb 1;38(2):178-83.

3. Haque KN. Isolated asternia: an independent entity. Clin Genet, 1984;25:362-5.

4. Kotzot D, Schwabegger AH. Etiology of chest wall deformities-a genetic review for the treating physician. J Pediatr Surg, 2009;44: 2004-11.

5. Ramfrez-Solis R, Zheng H, Whiting J, Krumlauf R, Bradley A. Hoxb-4 (Hox-2.6) mutant mice show homeotic transformation of a cervical vertebra and defects in the closure of the sternal rudiments. Cell. 1993 Apr 23;73(2):279-94.

6. Chellaoui M, Chat L, Achaabal F, Alami D, Najid A, Benamour-Ammar H. Fissure sternale congénitale totale à propos d'un cas. Médecine du Maghreb. 2001;90(3):16-8.

7. Lannelongue M. De le'ctocardie et de sa cure par autoplasie. Ann Med Chir, 4:101, 1888

8. Burton J. Method of correction of ectopia cordis. Arch Surg, 54:79-84, 1947

9. Maier HC, Bortone F. Complete failure of sternal fusion with herniation of perdicardium. Report of a case corrected surgically in infancy. $J$ Thorac Surg, 1949;18:851-9.

10. Jadhav V, Rao S, D'Cruz A. Autologous repair of isolated complete sternal cleft in an adolescent. J Pediatr Surg, 2009;44:2414-6.

11. Mathai J, Cherian VK, Chacko J, Sen S, Karl S, Pandyan MS, Mathew AK. Bridging the cleft over the throbbing heart. The Annals of thoracic surgery. 2006 Dec 1;82(6):2310-2311. 